Research, part of a Special Feature on New Methods for Adaptive Water Management

\title{
Managing Change toward Adaptive Water Management through Social Learning
}

\author{
$\underline{\text { Claudia Pahl-Wostl }}^{1}$, Jan Sendzimir $^{2}, \underline{\text { Paul Jeffrey }}^{3}$, Jeroen Aerts $^{4}$, Ger Berkamp $^{5}$, and \\ Katharine Cross $^{5}$
}

\begin{abstract}
The management of water resources is currently undergoing a paradigm shift toward a more integrated and participatory management style. This paper highlights the need to fully take into account the complexity of the systems to be managed and to give more attention to uncertainties. Achieving this requires adaptive management approaches that can more generally be defined as systematic strategies for improving management policies and practices by learning from the outcomes of previous management actions. This paper describes how the principles of adaptive water management might improve the conceptual and methodological base for sustainable and integrated water management in an uncertain and complex world. Critical debate is structured around four questions: (1) What types of uncertainty need to be taken into account in water management? (2) How does adaptive management account for uncertainty? (3) What are the characteristics of adaptive management regimes? (4) What is the role of social learning in managing change? Major transformation processes are needed because, in many cases, the structural requirements, e.g., adaptive institutions and a flexible technical infrastructure, for adaptive management are not available. In conclusion, we itemize a number of research needs and summarize practical recommendations based on the current state of knowledge.
\end{abstract}

Key Words: adaptive management; integrated water resources management; social learning; adaptive governance; change management; uncertainty

\section{INTRODUCTION}

In the past, water resources management focused on well-defined problems that grew increasingly urgent during the 19th and 20th centuries as urban populations became more concentrated and industrial and agricultural productivity intensified. Public health problems within cities and the seemingly insatiable demand for more water drove major efforts in urban water management. Eutrophication problems in lakes and coastal seas triggered more involved research and legislation. Rivers were controlled to protect cities and dryland agriculture from flooding. In the short run, technological fixes proved to be very efficient in solving a number of these urgent environmental problems, e.g., the increasing sophistication of wastewater treatment plants addressing problems related to hygiene and pollution. However, these problems were generally dealt with in isolation, and potentially undesirable long-term consequences were not taken into consideration. The system paradigm on which traditional water management has been based has often been characterized as a "command-and-control" approach. System design was typically targeted at high predictability and controllability.

For the past two decades, new and more integrated approaches to water management have been developed and are being implemented to address perceived shortcomings in earlier approaches. During the last decade, the principle of integrated water resources management (IWRM) has, for example, been used as a framework for the implementation of such integrated approaches to water management (GWP-TEC 2000). "Integrated" clearly indicates a desire to functionally engage a range of perspectives by formally considering a wide range of potential trade-offs at different scales

\footnotetext{
${ }^{1}$ University of Osnabrueck, ${ }^{2}$ International Institute for Applied Systems Analysis, ${ }^{3}$ Cranfield University, ${ }^{4}$ Vrije Universiteit Amsterdam, ${ }^{5}$ IUCN - The World Conservation Union
} 
in space and time. Such an approach attempts to overcome the shortcomings of technical end-ofpipe solutions that deal with individual problems in isolation and run the risk of causing unexpected consequences (Pahl-Wostl 2007a). However, the implementation of an IWRM approach that fully accounts for the complexity and interdependencies of human-technology-environment (HTE) systems has yet to be realized. The increasing awareness of the complexity of environmental problems and of HTE systems has encouraged the development of new management approaches based on the insight that the systems to be managed are, in broad terms, complex, unpredictable, and characterized by unexpected responses to intervention (Committee on Grand Canyon Monitoring and Research 1999, Pahl-Wostl 2002, Prato 2003, Pahl-Wostl 2007b; S. Light and K. Blann, unpublished manuscript). Such complex adaptive systems are characterized as hierarchies of components interacting within and across scales, with emergent properties that cannot be predicted by knowing the components alone (Lansing 2003). Control is distributed rather than central (Allen and McGlade 1985, Pahl-Wostl 1995). Rather than trying to change the structure of complex, adaptive systems to make them controllable by external intervention, innovative management approaches aim to make use of the selforganizing properties of the systems to be managed.

Increasing awareness of complexity is a necessary but not a sufficient condition for changing water management practices. Recent attempts (e.g., PahlWostl 2002, Galaz 2005, Jeffrey and Gearey 2006, W. Medema, B. McIntosh, and P. Jeffrey, unpublished manuscript) to manage water systems have revealed that major knowledge gaps in the following areas may impede the successful implementation of new management approaches.

\section{The management paradigm}

Current approaches to realizing integrated water management build on the heritage of a commandand-control paradigm that has been dominating the water management community for decades. Such a paradigm requires that system behavior be highly predictable. The failure to implement integrated approaches may due less to the principle of integration itself than to the mental models that frame the process of its implementation.

\section{The conceptual foundation}

An understanding of the concepts involved in system change, especially when this occurs in surprising and nonlinear ways, is needed to make researchers ask questions and think about ways to manage change. Basic concepts of this type capture insights into what blocks or foments change over what area and for how long, all of which is key information for management decisions. Concepts such as resilience, vulnerability, and adaptive capacity can inspire new management approaches and help us to better understand and express the results of exploratory analyses of and experiments involving complex adaptive systems. These concepts can also help us understand how management influences system change. Concepts of this type can help to characterize water management regimes, by accounting for both their components and their interdependencies, and to analyze their performance under current and future drivers in terms of, e.g., reaching management objectives and the ability of the management regime to adapt to change. This conceptual foundation would be greatly improved by better integrating the complexity and unpredictability of policy and social learning processes. The implementation of water management policies in a given river basin must take into account its political, economic, and social realities and thus requires a transparent and open discourse between scientists and policy makers

\section{Transition processes}

Current water management regimes have evolved over decades, and changing them will take some time. How can we directly study and analyze transition processes when the scale of change approaches or exceeds the time horizon of academic projects or careers? A better understanding of the transition processes and the barriers and facilitators for change is essential to catalyze change and foster the implementation of a transition process toward integrated and adaptive resource and water management regimes. Management failures, despite superior technology and well-financed central control, give rise to a key question: How can we improve understanding and trust through a social process of learning and negotiated change?

We maintain that, in environmental, economic, and social terms, sustainable water management can be successfully implemented only if more attention is 
given to understanding and closing these knowledge gaps, including the need to deal with uncertainties. Numerous technical and quantitative approaches already exist to account for uncertainties in policy analysis and formulation (Morgan and Henrion 1990). Qualitative uncertainty can be tackled via a variety of participatory approaches targeted at achieving social learning processes and negotiations to reach consensus despite different perspectives (Gunderson et al. 1995, Newig et al. 2005; C. PahlWostl, M. Craps, A. Dewulf, E. Mostert, D. Tabara, and T. Taillieu, unpublished manuscript).

However, a change in the overall management paradigm is needed to account for all the uncertainties in a more comprehensive fashion. This paper describes how the principles of adaptive water management might improve the conceptual and methodological basis for achieving sustainable and integrated water management in an uncertain and complex world. Sections 2 through 5 address the following questions:

- What types of uncertainty need to be taken into account in water management?

- What is adaptive management, and how does it account for uncertainty?

- What are the characteristics of adaptive management regimes?

- What is the role of social learning in managing change in the context of adaptive management?

\section{WATER MANAGEMENT AND THE NEED TO TAKE UNCERTAINTIES INTO ACCOUNT}

Because of a tradition rooted in the hydrological and engineering sciences, water managers have a vast array of experiences, methods, and tools with which to address environmental and quantifiable uncertainties. However, the knowledge and methods needed to address uncertainties in learning and decision-making processes are largely lacking. Rogers and Hall (2003) make plain the need for governance systems to be more flexible and to take uncertainty into account. Rees (2003) addresses the need for new strategies to manage risks in integrated water resource management and emphasizes the need to consider economic, social, and political uncertainties, which are often of more importance than environmental uncertainties. By embracing a wider perspective, it is possible to distinguish the different types of uncertainty that need to be taken into account when addressing a management problem (Funtowicz and Ravetz 1990, Pahl-Wostl et al. 1998, Oberkampf et al. 2001, Walker et al. 2003).

\section{Types of uncertainty}

The best-known type of uncertainty is a lack of knowledge because of the limited availability and the variability of data. Quite a few technical approaches exist to include such uncertainties in simulation models. Uncertainties may be captured by including uncertainty bounds in results from model simulations or other types of quantitative assessments.

An equally important but often less recognized type of uncertainty is uncertainty in our understanding of the system itself, not only its historical trends but also the system elements and interactions, including nonlinearities, feedback loops, and delays, that generate those trends. This applies in particular to socioeconomic systems and human behavior in those cases in which there is more than one possible interpretation of the same phenomenon. Also, our understanding of ecosystems is not as well developed as that of hydrological systems, the home turf of many scientists and practitioners working in water management. Furthermore, integrated water management requires an understanding of the full complexity of coupled human-environmenttechnology systems.

Another source of uncertainty inherent in system behavior rather than in the knowledge about it is the unpredictability of certain factors. In loosely coupled systems, the trajectory a system follows depends greatly on the original conditions around which it self-organizes. One prominent example is climate change and corresponding changes in nature and the likelihood of extreme events.

Uncertainty may also arise from the diversity of the rules and underlying mental models that determine and possibly constrain stakeholder perceptions and actions. Stakeholders may have different ideas about the causes of problems and appropriate and 
legitimate solutions, and use these ideas to construct quite different concepts of what is at stake, the goals to be achieved, the likelihood of the success of a particular measure, etc. The simultaneous presence of multiple frames of reference when seeking to understand a phenomenon is also called "ambiguity" (Dewulf et al. 2005).

What does such a broad understanding of uncertainty imply for the different steps in the management cycle, particularly in terms of the ways in which different kinds of uncertainties can be assessed as part of the whole sequence of steps, from defining the problem to monitoring the performance of the management strategies implemented?

\section{Problem definition}

Ambiguity, i.e., the possibility of more than one interpretation, is often encountered when defining the nature of the problem such as this: Is nitrate pollution of groundwater by agriculture caused by a profit-maximizing agricultural industry or by the refusal of consumers to pay higher prices for agricultural products? Even when the strategic management goal is prescribed by law, e.g., the European Water Framework Directive, the setting of operational targets in areas such as the desirable ecological state of a river and the acceptable economic impacts of management measures is open to interpretation. Given uncertainties in the data, more than one legitimate interpretation may be compatible with the available body of knowledge. Different perceptions and conflicts of interest thus require participatory problem definition and goal setting, although not by experts alone, plus a clear recognition of the uncertainties in this process.

\section{Choice of measures}

The outcomes of management measures are uncertain because of the complexity of the system to be managed and uncertainties in the environmental and socioeconomic developments that affect the performance of the chosen management strategies. As a result, robust strategies that perform well under a wide range of uncertain but possible future developments might be chosen over strategies that perform best under certain conditions but fail if those conditions are not met (J. C. J. H. Aerts, W. Botzen, A. Van der Veen, J. Krykrow, and S. Werners, unpublished manuscript).

\section{Implementation of measures and monitoring of performance}

New knowledge about system behavior or changes in environmental and/or socioeconomic conditions may demand changes in management strategies. When actors behave differently than expected, management measures sometimes lead to undesirable effects. The relevance and meaning of indicators for success or failure may be judged differently by different groups, and thus lead to different assessments of the performance of management strategies.

In the face of these challenges, ignorance and/or negligence is not an appropriate way to deal with uncertainty in water management. Management first needs to broaden the public debate and understanding of such uncertainties and the consequences of failing to address them or learning to live with them. Adaptive management explicitly accounts for such uncertainties and also requires a basic rethinking of the role of management in an uncertain and changing world.

\section{ADAPTIVE MANAGEMENT}

Adaptive management can more generally be defined as a systematic process for improving management policies and practices by learning from the outcomes of management strategies that have already been implemented. Adaptive water management aims to increase the adaptive capacity of the water system by putting in place both learning processes and the conditions needed for learning processes to take place. As pointed out by Bormann et al. (1993), "Adaptive management is learning to manage by managing to learn." In this case, learning encompasses a wide range of processes that span the ecological, economic, and socio-political domains in the testing of hard and soft approaches (Pahl-Wostl 2002, Gleick 2003). In this respect, adaptive management emphasizes the importance of the management process rather than focusing on goals, but without claiming that the process is an end in itself. It explicitly recognizes that management strategies and even goals may have to be adapted during the process as new information becomes available, and that the quality of the process, e.g., who is involved and which kind of information is taken into account, is essential for the outcomes finally achieved. 
Among environmental scientists, adaptive management is generally best known because of its application in the field of ecosystem management. The idea of adaptive management has been discussed in ecosystem management for quite some time (Holling 1978, Walters 1986, Pahl-Wostl 1995, Lee 1999). Adaptive management acknowledges that our ability to predict the future key drivers of any given ecosystem, as well as system behavior and responses, is inherently limited. As a result, management must include the ability to change management practices by incorporating the insights gained from past experience. A most influential publication on this topic was the seminal book of Walters (1986), who claimed that scientific understanding will come from the experience of management as an ongoing, adaptive, and experimental process, rather than through basic research or the development of ecological theory. What has been perceived as the most effective form of adaptive management, known as active adaptive management, uses management programs that are designed to experimentally compare selected policies or practices by evaluating alternative hypotheses about the system being managed (e.g., Gunderson et al. 1995, Kiker et al. 2001, Richter et al. 2003). This implies that hypotheses can be generated and tested via the outcomes of experiments. However, when extending management to social-ecological systems, we must recognize that testing hypotheses about human behavior is not the same as testing hypotheses about the dynamics of ecosystems. Actors may change the rules under which they operate when they are exposed to a model of themselves and confronted with the possible consequences of their behavior. Here, experiments and the generation of hypotheses may support processes of social learning that develop the capacity of the actors to deal with uncertainties and to learn from experience. Adaptive management supports reflexive governance, and the actors within the system adopt the strategy of rethinking and renegotiating their assumptions.

Adaptive management includes at its core an assessment and learning cycle. Close inspection of an AEAM (Adaptive Environmental Assessment and Management) learning cycle (Fig. 1) shows that it can be portrayed as a recasting of the scientific method of hypothesis testing, coupled interactively with modeling, such that it is fully integrated with the formulation of policy and the implementation or management of action plans based on policy. Hypotheses refer to working assumptions that make it possible to structure arguments and the policy debate. Modeling permits careful elaboration of the system structure and quantitative relations implied in hypotheses such that participants in the process can explore the dynamic implications of each hypothesis under different scenarios. Policy within the scientific context is seen more as an expression of how to test the hypotheses or questions generated during assessment. This experimental framework relieves decision makers of the responsibility to deliver policies as "solutions," but it challenges them to join the experiment and test, rather than defend, assumptions. Getting stuck with a policy, even one that started as a good policy, strangles innovation and understanding in a changing world. Therefore, striving to answer good questions, i.e., inquiry, is as important as implementing good policy, i.e., management. The latter should be part of the former, and vice versa.

To take into account the different kinds of uncertainties (see Section 2) and to implement and sustain the capacity for change, the whole process of policy development and implementation requires a number of steps that are part of an iterative cycle as represented in Fig. 2. All of these steps should be participatory. In the definition of the problem (0), different perspectives need to be taken into account. The design of policies (1) should include scenario analyses to identify key uncertainties and find strategies that perform well under different possible, but initially uncertain, future developments; this is preferable to searching for the best strategy for very specific conditions, e.g., climate, because that strategy may not perform well if those conditions are not met. Policies must be understood as semiopen experiments that require a careful evaluation of potential positive or negative feedback mechanisms by planning and implementing other related policies $(1,2)$. Decisions should be evaluated in part by how much it would cost to reverse them. Large-scale infrastructure or rigid regulatory frameworks increase the costs of change, but costs may also be related to a loss of trust and credibility if uncertainties and the possible need for changes are not addressed by the competent authority during policy development (3). The design of monitoring programs should include processes that can pinpoint undesirable developments at an early stage. This might imply different kinds of knowledge, including community-based monitoring systems (3). The policy cycle must include support for institutional settings in which actors assess the performance of management strategies and 
Fig. 1. Iterative process of model development linked to policy formulation whose evaluation stimulates reassessment of the problem (after Sterman 2000).

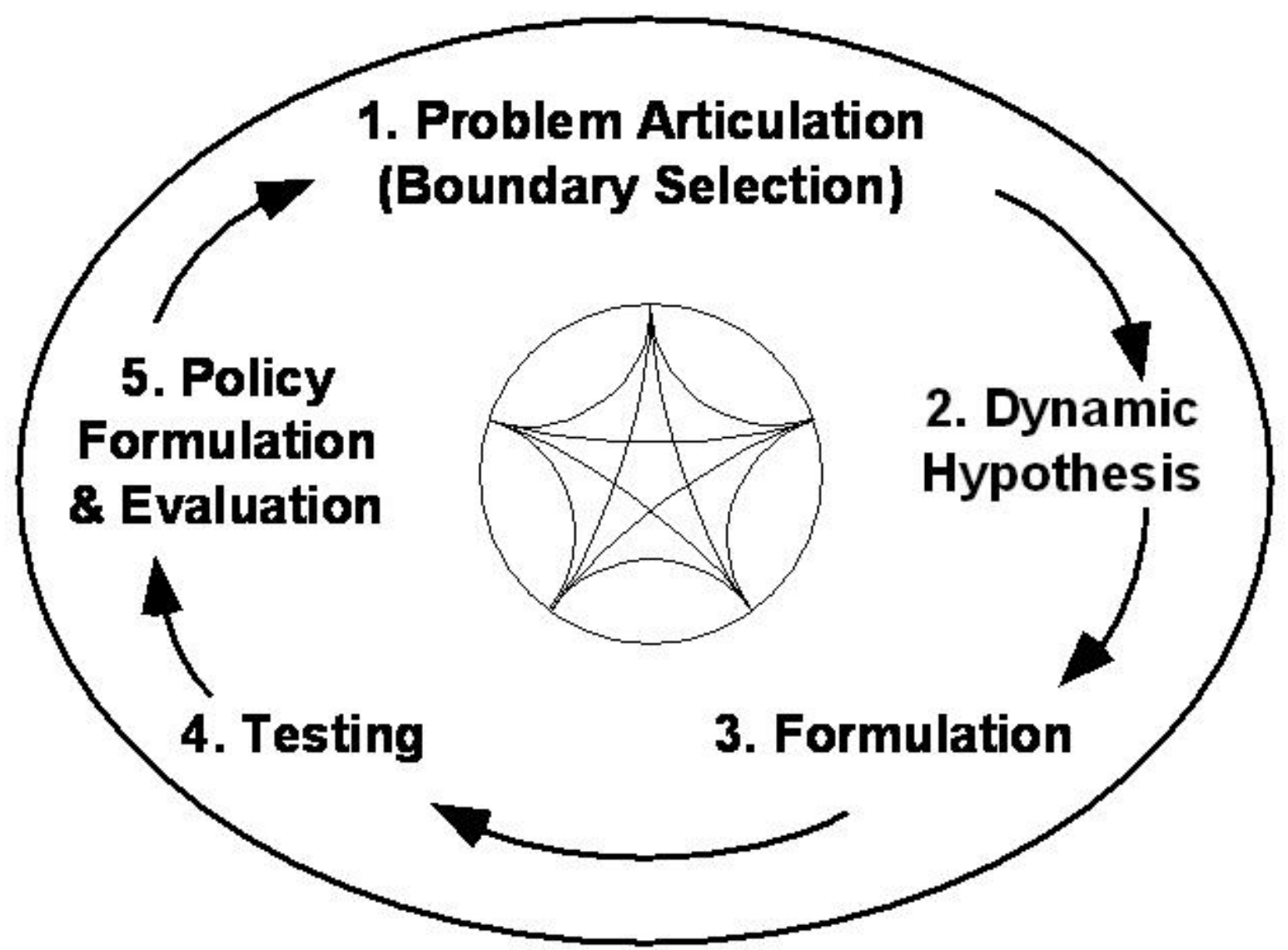

implement change if needed (4). Continuous replanning and reprogramming based on the results of monitoring and evaluation should be institutionalized (4).

Moberg and Galaz (2005) introduce "adaptive comanagement" as a new term that emphasizes the collaboration between agencies, researchers, and local stewards and contrast this concept with that of adaptive management, which they refer to as embracing a top-down governance approach. We do not consider it necessary to introduce yet another term and concept. The definition of adaptive management is broad enough as it stands and in no way excludes a polycentric governance approach (D. Huitema, W. Egas, S. Möllenkamp, E. Mostert, C. Pahl-Wostl, and R. Yalcin, unpublished manuscript). Its implementation should be based on a participatory assessment and implementation process that takes into account the particular institutional, cultural, and socioeconomic contexts in a given river basin.

Furthermore, research shows the importance of managing uncertainty and unexpected shocks to a system by using a more flexible and diverse management style. For example, Fraser et al. (2005) base their view of the importance of portfolio 
Fig. 2. Iterative cycle of policy development and implementation in adaptive management.

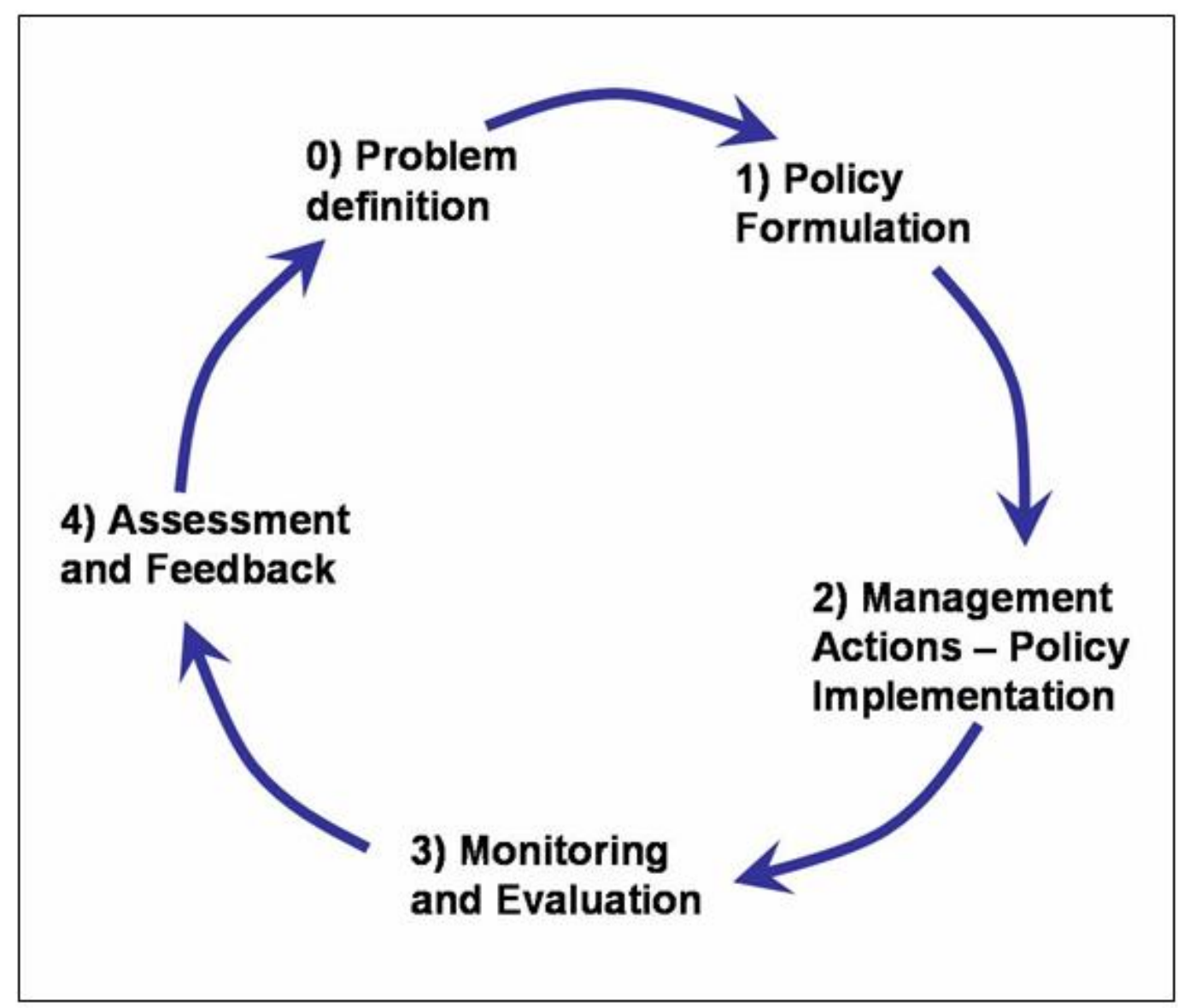

management and diversifaction in reducing vulnerability in agro-environmental systems on panarchy theory (Gunderson and Holling 2002). A number of researchers (J. C. J. H. Aerts, W. Botzen, A. Van der Veen, J. Krykrow, and S. Werners, unpublished manuscript; J. C. J. H. Aerts and S. Werners, unpublished manuscript) are working on concepts applicable to portfolio management and diversification in water management. Extensive literature on diversification in management as a means of becoming more adaptive is found in financial research (e.g., Markovitz 1952), and more recently in biodiversity research (Figge 2004).
Finally, integrating learning with changes in policy is possible only if the policies already implemented can be changed. The transition to adaptive management relies on increasing the adaptive capacity of the (water) system by meshing management and policy with learning. Adaptive management aims to design integrated systems based on an understanding of the interdependence between technologies, economic factors, and formal and informal institutions. The problem to be tackled is to increase the ability of the whole system to learn about and change the context within which it responds to change, rather than reacting to 
undesirable impacts of change. Institutionalizing this learning capability over the long term will secure the adaptive foundation of management.

Adaptiveness suggests a diversity of means available to address a challenge. Confining one's approach, even in the attempt to become adaptive, to a single method could constrain adaptiveness over the longer term. There is no ideal path to adaptiveness. Choosing the most appropriate management approach may depend on how well it satisfies certain criteria at this stage of development (see van Eeten and Roe 2002 for other alternatives). For example, one may ask if current water management regimes that have evolved under a very different management paradigm possess the structural requirements needed to implement adaptive management approaches.

\section{ADAPTIVE MANAGEMENT REGIMES}

A management regime is here referred to as the whole complex of technologies, institutions, environmental factors, and paradigms that are highly interconnected and essential to the functioning of the management system that is targeted to fulfill a societal function such as water supply or flood protection. It is noted that "institution" is used to refer to the formal, e.g., laws, and informal, e.g., norms, rules that determine the behavior of actors, but not to the physical structures that are referred to as organizations. Because of their high interconnectedness and internal logic, it is assumed that the individual elements of the regime cannot be exchanged arbitrarily. A transition from centralized water treatment technologies to decentralized technologies at household scale requires, for example, major changes in the roles of actors, legal regulations, consumer habits, etc. (Panebianco and Pahl-Wostl 2006). How a regime's performance is influenced by these factors and their relationships can be one basis of analysis.

Another approach is to assess a regime's capacity to be adaptive based on how well its performance meets certain requirements that can be summarized as follows:

- New information must be available and/or collected, e.g., performance indicators and indicators of change that may lead to desirable or undesirable effects, and monitored over appropriate time scales that are generally longer than those mandated by short-term political objectives.

- The actors in the management system must be able to process this information and draw meaningful conclusions from it. This can be achieved if a learning cycle and negotiation process unite the actors in all phases of assessment, policy implementation, and monitoring. Because actors pursue different and changing political interests, transparency and leadership are of major importance to make such multiparty negotiation processes work.

- Change must be possible in ways that are open and understandable to all the actors. Managers must be able to implement change based on new information, processed in a transparent manner, that makes it clear who decides how and when to change management practices and what evidence was used to make this decision. To do this, it is necessary to strike a balance between continuity and flexibility, because some management strategies may take one or more decades to be implemented and tested.

An important question is whether current management regimes allow the implementation of management approaches that meet the requirements listed above. If the regimes evolved under another management paradigm, then this is probably not the case. Some structural requirements that are likely to make a system adaptive have been summarized in Table 1. This table contrasts two regimes that differ significantly in terms of five characteristics in the following table (Pahl-Wostl et al. 2005, PahlWostl 2007b). Regime typologies generally reject the idea of an infinite variety of approaches and are based on the assumption that management regimes can be classified into different groups based on some internal logic of coherent characteristics. The characteristics of integrated adaptive regimes are to be regarded as working hypotheses, because the change toward more adaptive regimes is slow and available empirical evidence is limited. One possible reason for this lack of innovation is the strong interdependence of the factors stabilizing current management regimes. One cannot, for example, move easily from top-down to participatory management practices without changing the whole approach to information and risk management. Hence, research is urgently 
needed to better understand the interdependence of key elements of water management regimes and the dynamics of transition processes, so that we can compare and evaluate alternative management regimes and implement and support transition processes if required.

The transition from a prediction-and-control to an integrated adaptive regime is difficult. One reason for this is the obstacles that impede the practical implementation of adaptive management, such as the high costs of information gathering and monitoring, resistance from managers who may fear increased transparency and loss of control, political risks because of the uncertainty of future benefits, the lack of stable funding, and fear of failure (Lee 1993). In an analysis of the implementation of the adaptive management framework in the Florida Everglades, Gunderson (1999) identified three major barriers to the successful implementation of adaptive management: inflexibile social systems, ecological systems that lack resilience, and the technical challenges associated with designing experiments.

Institutional challenges can also restrict the usefulness of adaptive management approaches. For example, Lee (1993) identifies complicated social dynamics and institutional rigidities as possible barriers to the successful application of an adaptive management approach. Institutional needs for information are an associated feature here. Learning is information-intensive and requires active stakeholder participation (Margoluis and Salafsky 1998). The level of cooperation that is required to gather the information needed for adaptive management indicates that many different stakeholders need to maintain a commitment to the learning process.

To initiate the transition to adaptive management, there must be widespread dissatisfaction with the current or anticipated performance of existing management strategies, those involved must have the ability to detect and monitor potential gaps between the achieved and desired goals of the current management system, and those involved must be willing to change. In this type of process, the initial phase is particularly crucial, and the development of informal actor networks can contribute to success (Olsson et al. 2006, PahlWostl et al. 2006). An alternative perspective on policy and change is necessary in situations in which social learning processes are precursors to more adaptive management regimes.

\section{PROCESSES OF CHANGE AND THE ROLE OF SOCIAL LEARNING}

\section{The role of social learning in understanding and managing change}

Why is social learning needed in the transition to
adaptive water management?

As pointed out in the previous section, there is often a mutual dependence among regime elements such as technical infrastructure, e.g., large technical infrastructure for flood protection; citizen behavior, e.g., expectations regarding safety in floodplains, risk perception; and engineering rules of good practice. In many cases they have co-evolved over a long period of time. Mutual relations of this type can develop into pathological path dependence or so-called "lock-in" situations that block changes toward new resource management schemes and require collective learning and decision-making processes (Pahl-Wostl 2002). To escape lock-in, actors need to learn to recognize how their own frames of reference influence and constrain their thinking and that other legitimate frames of reference exist. Collective action and the resolution of conflicts require that people recognize their interdependence and their differences and learn to deal with them constructively. Mutual recognition of shared paradigms can open the door to compromise. The different groups need to learn and increase their awareness of their biophysical environment and the complexity of social interactions. This does not imply that a consensus must be achieved, but what is required is the development of a minimum level of trust as a basis for transparent and efficient communication. Social learning in river basin management is needed to develop and sustain the capacity of different authorities, experts, interest groups, and the public to manage their river basins in a sustainable way and balance multiple and competing interests for the benefit of the social-ecological system as a whole.

\section{Social learning for adaptive management}

A concept for social learning in river basin management has been developed in the context of the European project HarmoniCOP (Harmonizing COllaborative Planning). The main objectives of HarmoniCOP (www.harmonicop.info) were to increase the understanding of participatory river basin management in Europe; generate practical, useful information about and improve the scientific 
Table 1. Ideal-typical characterizations of a prediction-and-control and an integrated adaptive water management regime.

\begin{tabular}{lll}
\hline \hline Characteristic & Prediction-and-control regime & Integrated adaptive regime \\
\hline Governance structure & $\begin{array}{l}\text { Governance is centralized and } \\
\text { hierarchical, with narrow stakeholder } \\
\text { participation. }\end{array}$ & $\begin{array}{l}\text { Governance is polycentric and horizontal, with } \\
\text { broad stakeholder participation. }\end{array}$ \\
Sectoral integration & $\begin{array}{l}\text { Sectors are separately analyzed, } \\
\text { resulting in policy conflicts and the } \\
\text { emergence of chronic problems. }\end{array}$ & $\begin{array}{l}\text { Cross-sectoral analysis identifies emergent } \\
\text { problems and integrates policy implementation. }\end{array}$ \\
$\begin{array}{l}\text { Scale of analysis and } \\
\text { operation }\end{array}$ & $\begin{array}{l}\text { Transboundary problems arise when } \\
\text { river sub-basins are the exclusive scale } \\
\text { of analysis and management. }\end{array}$ & $\begin{array}{l}\text { Transboundary issues are addressed by multiple } \\
\text { scales of analysis and management. }\end{array}$ \\
Information management & $\begin{array}{l}\text { Understanding is fragmented by gaps } \\
\text { and the failure to integrate information } \\
\text { sources that are proprietary. }\end{array}$ & $\begin{array}{l}\text { Comprehensive understanding is achieved by } \\
\text { open, shared information sources that fill gaps } \\
\text { and facilitate integration. }\end{array}$ \\
Infrastructure & $\begin{array}{l}\text { A massive, centralized infrastructure has } \\
\text { single sources of design, power, and } \\
\text { delivery. }\end{array}$ & $\begin{array}{l}\text { A decentralized infrastructure on an appropriate } \\
\text { scale has diverse sources of design, power, and } \\
\text { delivery. }\end{array}$ \\
Finances and risk & $\begin{array}{l}\text { Financial resources are concentrated in } \\
\text { structural protection, i.e., sunk costs. }\end{array}$ & $\begin{array}{l}\text { Financial resources are diversified using a broad } \\
\text { set of private and public financial instruments. }\end{array}$
\end{tabular}

base of social learning and the role of information and communication technology tools in river basin management; and support the implementation of the European Water Framework Directive The approach adopted by the HarmoniCOP project is characterized by a broad understanding of social learning that is rooted in the more interpretative strands of the social sciences. Figure 3 represents the framework for social learning developed to account for learning processes in actor networks in water resources management (Pahl-Wostl 2002, Craps et al. 2003, Bouwen and Taillieu 2004). The framework is structured into context, process, and outcomes, plus a feedback loop to account for change in a cyclic and iterative learning process. The context refers to the governance structure and the natural environment in a river basin. To improve the state of the environment implies in practice most often a change in the governance structure. The process refers to multiparty interactions in formal or informal negotiations; processes of this type are at the heart of iterative policy cycles (see Fig. 2).
Social learning is assumed to occur at two levels: (1) at short to medium time scales, it occurs at the level of processes between actors, and (2) at medium to long time scales, at the level at which structural context shifts the governance structure.

One distinct feature is the emphasis on relational processes, which takes into account the fact that dealing with factual information about a problem is always embedded in a context of negotiated meaning.

The process concept that refers to multiparty interactions in actor networks has two pillars (Fig. 3 ). They relate to the processing of factual information about a problem, i.e., content management, and engaging in processes of social exchange, i.e., social involvement. Social involvement refers to essential elements of social processes, such as the framing of the problem, the management of the boundaries between different stakeholder groups, the type of ground rules and 
Fig. 3. Conceptual framework for social learning in resources management. In the center are multiparty processes that are influenced by the context in which they are embedded and that produce outcomes that may lead to changes in the context, and thus to a cyclic and iterative long-term process of change.

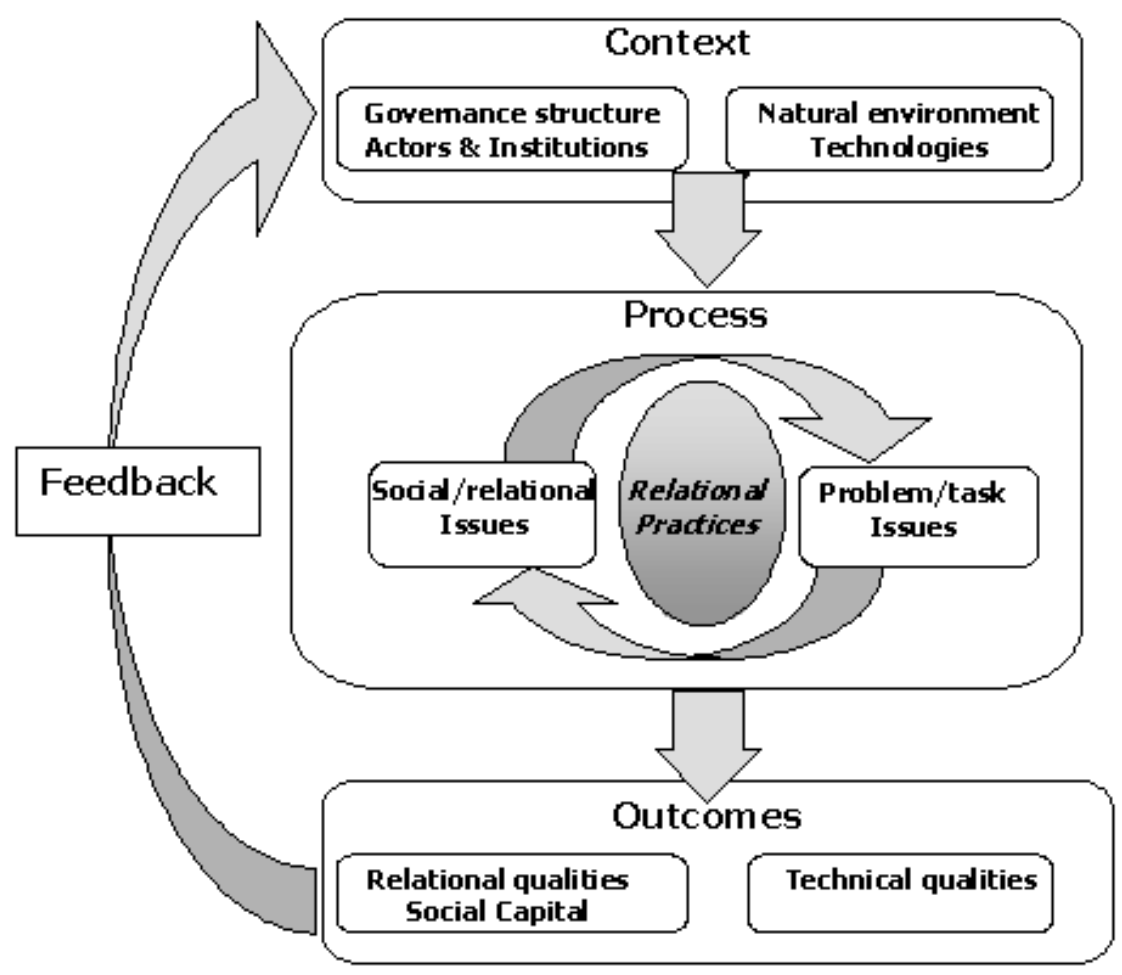

negotiation strategies chosen, or the role of leadership in the process. As an example, the role of framing is explained in more detail.

\section{Framing}

During the initial stages of dealing with a problem, the framing and reframing of a problem domain determine the direction of the overall process. Frames may be derived from the culture, social roles, scientific disciplines, etc. Actors have frames that determine how they make sense of and interpret information and their physical and social environment. Differences in how an issue is framed are among the key reasons for problems in communication and entrenched conflicts among actors. The framing of an issue includes, for example, what is at stake, who should be included, and which roles the different actors should play. Processes of framing and reframing are essential elements of group social dynamics during the negotiation of the meaning of key issues such as the goals to be achieved or how to measure management success. Experienced negotiators know that 
powerful actors often impose their frames or interpretations of an issue onto a process. A relational practice may be a moderated role-playing game or policy exercise in which actors are willing to reflect and discuss their own perspectives as well as listen to others. This type of social learning does not necessarily lead to consensus, but develops the ability to deal with differences constructively when transparency makes clear everyone's intentions.

A central hypothesis of the concept of social learning is that social involvement and the management of content are strongly interdependent and cannot be separated. The overall process aims to improve both technical qualities, such as the improvement of the state of the environment, and relational qualities, such as an increase in the capacity of a stakeholder group to manage a problem and/or institutional change. This leads as well to a different interpretation of the role of information and of information and communication tools and the ability of an actor network to use new information in social learning processes and to determine collective action. Knowledge relevant for decision making cannot be reduced to objective facts devoid of context and subjective interpretation. The development of joint interpretations and the implementation of collective action need to integrate tacit knowledge, which is not externalized and codified and can thus only be shared through joint activities that require physical proximity (Nonaka 1991). Participatory methods such as group model building and role-playing games are based on relational practices and can thus support social learning in actor groups (Pahl-Wostl and Hare 2004, Maurel et al. 2007). Such learning environments are perceived to be crucial for the adaptive governance of social-ecological systems (Folke et al. 2005, Pahl-Wostl 2005). Hence, an entirely new element of monitoring refers to the quality of the communication process in actor networks and the appropriateness of the chosen institutional setting.

Such multi-actor processes are embedded in a structural governance context that has a strong influence and may constrain or facilitate learning processes (Tippett et al. 2005).

\section{Toward guidance for managing change}

The discussion in the previous section on social learning in actor networks developed the image of dynamic and multilevel policy arenas and highlighted the fact that there may be barriers to change, given the importance of context and path dependence. How can we guide and manage change to overcome such barriers?

As highlighted in Fig. 3, decisions and the management of water resources do not take place in isolation, but are rather complex political processes that take shape at different semiautonomous political levels. To link this understanding to concrete political actions it may be useful to distinguish the following levels explicitly (Pahl-Wostl et al. 2006):

- The context level incorporates the wider political and institutional environment that determines the governance structure.

- The network level refers to the policy arenas that determine the participating actors and type of institutions, i.e., who is in and who is out of the process, and thus also to the boundaries and framing of the problems and solutions taken into account.

- The social interaction or game level deals with the institutions and rules that shape individual behavior and collective negotiation and the learning and decision-making processes. Such interactions are referred to here as games in which rules determine the positions of the actors, the actions they can take, etc.

Understanding how, at the levels of context, networks, and games, actors and institutions create perceptions and make use of tools is critical for the adaptive management of water resources. The hierarchical levels described are not controlled through top-down authority, but operate semiindependently through sets of interactions among variables operating on similar planes. For example, the context level would refer to decision spaces for adaptive management operating over decades, whereas the game level would shape management options over weeks or months. The coupling between the various levels shapes the outcome of 
decisions about water management and investments and hence determines the adaptive capacity of the water sector or of a specific river basin.

These ideas form the basis of a coherent framework for analyzing the political context within which an adaptive capacity needs to be developed for river basin management. Table 2 summarizes 12 political actions that actors need to consider if they wish to develop adaptive capacity for the management of a river basin. These actions require active social learning that involves perceptions, tools, actors, and institutions at the context, network, and game levels. In the following subsections the different actions are described in more detail.

\section{The context level}

The context level refers to the wider context within which river basin management takes shape. It refers to societal views, national constitutions and laws, the approaches and tools used for management, and the existing landscape of actors and institutions that is formed over long periods of time. It typically affects the management of several river basins because it generally constrains and determines practices at larger spatial scales, such as countries or socioeconomic regions. The two main activities that take place at the context level are:

- $\quad$ shaping and developing. Actors at the context level can shape the context and discourse (Olsson et al. 2006) within which networks are managed and games are conducted by using opportunities to change existing water policies. New tools or mechanism can be developed that can change the way networks and policy actors find solutions to water allocation problems.

- grouping and creating. Stakeholders in river basins and at national levels often cluster in different groups that hold similar views or interests. Creating or (re-)grouping actors either at national levels or within a river basin can help to change the way a policy network is managed or functions. Although different actors can cluster in different ways, another option is to create new (groups of) institutions. This often happens at the national level when a new water policy is developed and the existing institutional setup needs to be brought into line with the policy. Institutions also refer to social norms that may strongly influence policy development and implementation, an influence that should be made explicit.

\section{The network level}

The network level refers primarily to the provincial context of river basin management, even though basins span continents. It pertains to the relationships established between interdependent institutions and how they do or do not cooperate. The context level determines how the network level will be formed and function, and in turn the network level determines how organizations will play the game, i.e., their approach to decision making and their attitudes to new tools for river basin management. The network level is formed over years and usually applies to the management of a regional river basin. At the network level, the actors focus on:

- reframing and selecting. Social learning includes the reframing of problems to make sense of available information and assess its use in adaptive river basin management. The network can also be used as a tool to bring forward ideas and reframe river management problems into a more manageable form. Traditional instruments, such as existing regulations used for river basin management, may not be very effective within a network; instead, instruments must be selected and altered to fit the frame of reference of the network. The tools selected and adapted for the network depend on the actors that make up the network and the relationships that exist between the actors (Kickert et al. 1999).

- activating and reforming. Sometimes new actors are activated, i.e., created or brought into a network to carry out functions needed to manage the network. New actors can be introduced by setting up or reorganizing a commission, recruiting them, or bringing in an advisor (Kickert et al. 1999). For example, an association of business owners could be created to take part in public discussions about floodplain management to ensure that the interests of the business community are represented. Introducing a new party into a network does not automatically solve problems and create new ideas; rather, new ideas arise as a result of the interactions between the new and existing members of a 
Table 2. Water management hierarchies for adaptive management.

\begin{tabular}{lcccc}
\hline \hline Hierarchical levels & Perceptions & Tools & Actors & Institutions \\
\hline Context level & Shaping & Developing & Grouping & Creating \\
Network level & Reframing & Selecting & Activating & Reforming \\
Game level & Convenanting & Using & Switching & Arranging
\end{tabular}

network. Reframing problems through such interactions will lead to actual reformation through action. For example, institutions that are created or activated can be part of the reforming process in a network. Network management steers the process of reforming as perceptions shift and actors enter and leave the network.

\section{The game level}

Networks, which are the patterns of relationships between actors, are the context in which games take place. At the same time, games change and influence the shape of networks. Actors within networks choose strategies, i.e., policy-making processes, that seem rational according to the network they interact with, their individual goals, and the overall context of the policy-making process. Furthermore, the actors driving river basin management at the game level are influenced by other forms of management, e.g., agricultural management, and the relationships developed in the network through present and past interactions. A characteristic feature of a game is that the result derives from the interactions between the strategies of all the actors involved. The rules of the game interactions put constraints on actors but are at the same time the product of their interactions (Kickert et al. 1999). The game level includes individuals and organizations that make decisions over periods of several months. Their essential activities include:

- covenanting and using. Covenanting refers to a management strategy aimed at improving the consistency of the decisions made in the game by exploring and consolidating the perceptions of the actors involved (Klijn and Teisman 1997). The covenanting concept is used to emphasize that specialized actors, e. g., network managers, have the potential to enrich new initiatives. These actors may need to be trained to use the tools they manipulate to effectively play the game. For example, a tool kit for environmental flows can be developed to guide river basin management, but it may be of little use unless the actors are trained in how to apply the knowledge from the tool kit. This learning can evolve over time through interactions with other actors or through active training courses.

- $\quad$ switching on and arranging. Policy-making processes can be improved by figuratively switching on specific participants. Selective activation demands that managers assess which actors are essential at any given moment in the policy process, whether or not they should be involved, and how to involve them. The success achieved through activating and deactivating actors depends on choosing the appropriate actors, as well as the willingness and ability of actors to invest time and resources in a policy process. Arranging refers to the capacity of the participants involved to develop platforms on which games can be played and to their ability to develop or use rules for interaction. Arrangement as a management activity is the art of linking interdependent actors in such a way that rearrangements do not result in high transaction costs (Kickert 1999). Different actors may be brought in or new relationships forged to change the status quo and move forward on an issue. 


\section{CONCLUSIONS AND CHALLENGES}

A range of strong arguments supports the claim for a paradigm shift in water management. The emphasis on reducing complexity, externalizing the human dimension, and designing technical systems that can be controlled has resulted in quite rigid and inflexible management systems that do not perform well in times of uncertainty and change. To implement integrated management approaches that take into account the complexity of the systems to be managed requires a change in the understanding of what management implies, how and which kinds of uncertainties are addressed, and how risks are managed. Complex social-ecological systems cannot be predicted and controlled, and a more adaptive approach is required.

However, integrated and adaptive water management approaches cannot be implemented without profound structural changes. In industrialized countries with a strong prediction-and-control tradition of water management, a complete system redesign comprising technologies, organizational structure, regulations, and thus a major transition is needed. In many developing countries, the base for management has yet to be developed. The changes needed are no less profound, but these countries face entirely different problems. Many countries suffer from a lack of political stability and the absence of any reliable administration. The knowledge base and monitoring capacity for implementing water management are often missing. Building the capacity to manage water has to be seen in a larger context of socioeconomic development. Given these uncertainties, an adaptive and flexible management approach seems to be mandatory. These countries need to develop and implement management strategies tailored to their needs and the political and environmental context rather than trying to adopt blueprints for institutions or technologies that may be entirely unsuitable for their situation.

We argue that change and the design and implementation of integrated and adaptive, and thus sustainable, water management regimes cannot be brought about by top-down implementation but require a process of learning and change. This can be explored by recognizing how decisions evolve at the context, network, and game levels. Dynamic and flexible actor platforms are needed that allow different perspectives and the interpretation and negotiation of the different dimensions of sustainability. As numerous analyses have shown, learning often occurs in shadow networks outside the formal water management context. We argue that learning cycles should be implemented as a recognized and important element of the established management regime. Social learning is of major importance to initiate change in, to build, and to sustain the adaptive capacity of water management systems. A range of knowledge gaps still exists. Nevertheless, it is possible to make these recommendations for policy makers to develop, implement, and sustain adaptive management practices to support sustainable water management in times of increased uncertainty because of global change:

- The complex social-ecological nature of river basin environments and the inherent uncertainties associated with their management have to be taken into account in policy development and implementation.

- Management strategies should be robust and perform well under a range of possible, but uncertain, future developments. This might imply the need for a diversification in management measures.

- The design of transparent and open social learning processes is a key requirement of sustainable water management regimes.

- Effort has to be devoted to building trust and social capital for problem solving and collaborative governance.

- An increase in, and maintenance of, the flexibility and adaptive capacity of water management regimes should be a primary management goal.

- Entrenched perceptions and beliefs block innovation and change. Space has to be provided for creative and out-of-the-box thinking and experiments.

- There is a significant need to train a new generation of water management practitioners skilled in participatory system design and implementation. 
Implementing these recommendations would help develop the capacity to devise alternative management strategies and to choose between alternatives based on sound deliberation. There are reasons to be optimistic that these recommendations will fall on fertile ground. For a long time, discourse on radical change in water management has taken place in shadow networks. However, the political recognition and increased awareness of climate change and unprecedented experiences with failures of water management have opened up windows of opportunity in which the willingness to experiment with new approaches is much higher than it used to be. Future work on comparative analyses will still need to develop a sound classification of problems and associated uncertainties and processes suitable for the development and implementation of management approaches that take into account the characteristics of the environmental and societal context in which they are embedded.

Responses to this article can be read online at: http://www.ecologyandsociety.org/vol12/iss2/art30/responses/

\section{Acknowledgments:}

We would like to thank our partners in the NeWater project for numerous inspiring discussions on the themes elaborated in this paper, and Georg Holtz. and Art Dewulffor their critical review of an earlier draft of the current paper. The work presented in this paper was financially supported by the European Commission (Contract No. 511179 NEWATER).

\section{LITERATURE CITED}

Allen, P., and J. McGlade. 1985. Modeling complexity: the dynamics of discovery and exploitation in a fisheries example. Pages 49-76 in I. Prigogine and M. Sangliere, editors. Laws of nature and human conduct. Task Force on Research, Information and Study of Science, Brussels, Belgium.

Bormann, B. T., P. G. Cunningham, M. H. Brookes, V. W. Manning, and M. W. Collopy. 1993. Adaptive ecosystem management in the Pacific Northwest. U.S. Forest Service, General
Technical Report PNW-GTR-341.

Bouwen, B., and T. Taillieu. 2004. Multiparty collaboration as social learning for interdependence: developing relational knowing for sustainable natural resource management. Journal of Community and Applied Social Psychology 14:137-153.

Committee on Grand Canyon Monitoring and Research. 1999. Downstream: adaptive management of Glen Canyon Dam and the Colorado River ecosystem; report to National Research Council. National Academy Press, Washington, D.C., USA. Available online at: http://www.nap.edu/books/030 9065798/html/R1.html.

Craps, M., editor. 2003. Social learning in river basin management; report of workpackage 2 of the HarmoniCOP project. (http://www.harmonicop.uniosnabrueck.de/ files/ down/SocialLearning.pdf).

Dewulf,A., M. Craps, R. Bouwen, T. Taillieu, and C. Pahl-Wostl. 2005. Integrated management of natural resources: dealing with ambiguous issues, multiple actors and diverging frames. Water, Science and Technology 52:115-124.

Figge, F. 2004. Bio-folio: applying portfolio theory to biodiversity. Biodiversity and Conservation 13:827-849.

Folke, C., T. Hahn, P. Olsson, and J. Norberg. 2005. Adaptive governance of social-ecological systems. Annual Review of Environment and Resources 30:441-473.

Fraser, E. D. G., W. Mabee, and F. Figgre. 2005. A framework for assessing the vulnerabulity of food systems to future shocks. Futures 37:465-479.

Funtowicz, S. O., and J. R. Ravetz. 1990. Uncertainty and quality in science for policy. Kluwer, Dordrecht, The Netherlands.

Galaz, V. 2005. Does the EC Water Framework Directive build resilience? Harnessing socioecological complexity in European water management. Resilience and Freshwater Initiative Policy Paper. Swedish Water House, Stockholm, Sweden.

Gleick, P. 2003. Global freshwater resources: softpath solutions for the 21st century. Science 
302:1524-1528.

Global Water Partnership-Technical Advisory Committee (GWP-TAC). 2000. Integrated water resources management. TAC Background Papers, No. 4. GWP, Stockholm, Sweden.

Gunderson, L. 1999. Resilience, flexibility and adaptive management-antidotes for spurious certitude? Conservation Ecology 3(1):7. [online] URL: http://www.consecol.org/vol3/iss 1/art7.

Gunderson, L. H., and C. S. Holling, editors. 2002. Panarchy: understanding transformation in human and natural systems. Island Press, Washington, D.C., USA.

Gunderson, L. H., C. S. Holling, and S. S. Light, editors. 1995. Barriers and bridges to the renewal of ecosystems and institutions. Columbia University Press, New York, New York, USA.

Holling, C. S., editor. 1978. Adaptive environmental assessment and management. John Wiley, New York, New York, USA.

Jeffrey, P., and M. Gearey. 2006. Integrated water resources management: lost on the road from ambition to realisation? Water, Science and Technology 53(1):1-8.

Kickert, W. J. M., E.-H. Klijn, and J. F. M Koppenjan. 1999. Managing complex networks: strategies for the public sector. Sage, London, UK.

Kiker, C. F., J. W. Milon, and A. W. Hodges. 2001. Adaptive learning for science-based policy: the Everglades restoration. Ecological Economics 37:403-416.

Klijn, E.-H., and G. R. Teisman. 1997. Strategies and games in networks. Pages 98-118 in W. J .M. Kickert,, E.-H. Klijn, and, J.F.M Koppenjan, editors. Managing complex networks: strategies for the public sector. Sage, London, UK.

Lee, K. N. 1993. Compass and gyroscope: integrating politics and science for the environment. Island Press, Washington, D.C., USA.

Lee, K. N., 1999, Appraising adaptive management. Conservation Ecology 3(2):3.

[online] URL: http://www.ecologyandsociety.org/vol3/ iss $2 / \operatorname{art} 3 /$.
Margoluis, R., and N. Salafsky. 1998. Measures of success: designing, monitoring and managing conservation and development. Island Press, Washington, D.C., USA.

Markowitz, H. 1952. Portfolio selection. Journal of Finance 17:1.

Maurel, P., M. Craps, F. Cernesson, R. Raymond, P. Valkering, and N. Ferrand. 2007. Concepts and methods for analysing the role of IC-tools in SL processes for river basin management. Environmental Modelling and Software 22:630-639.

Moberg, F., and V. Galaz. 2005. Resilience: going from conventional to adaptive freshwater management for human and ecosystem compatibility. Swedish Water House Policy Brief, No. 3. Stockholm International Water Institute, Stockholm, Sweden.

Morgan, M. G., and M. Henrion. 1990. Uncertainty: a guide to dealing with uncertainty in quantitative risk and policy analysis. Cambridge University Press, Cambridge, UK.

Newig, J., C. Pahl-Wostl, and K. Sigel. 2005. The role of public participation in managing uncertainty in the implementation of the water framework directive. European Environment 15:333-343.

Newson, M. 1992. Land, water, and development: sustainable management of river basin systems. Routledge, London, UK.

Nonaka, I. 1991. The knowledge-creating company. Harvard Business Review 69:96-104

Oberkampf, W. L., J. C. Helton, C. A. Joslyn, S. F. Wojtkiewicz, and S. Ferson. 2001. Challenge problems: uncertainty in system response given uncertain parameters, Epistemic Uncertainty Project. Available online at http://www.sandia.gov/ epistemic/prob.statement.12-01.pdf.

Olsson, P., L. H. Gunderson, S. R. Carpenter, P. Ryan, L. Lebel, C. Folke, and C. S. Holling. 2006. Shooting the rapids: navigating transitions to adaptive governance of social-ecological systems. Ecology and Society 11(1):18 [online] URL: http:// www.ecologyandsociety.org/vol11/iss1/art18/.

Pahl-Wostl, C. 1995. The dynamic nature of 
ecosystems: chaos and order entwined. Wiley, Chichester, UK.

Pahl-Wostl, C. 2002. Towards sustainability in the water sector: the importance of human actors and processes of social learning. Aquatic Sciences 64:394-411.

Pahl-Wostl, C. 2006. The importance of social learning in restoring the multi-functionality of rivers and floodplains. Ecology and Society 11(1):10. [online] URL: http://www.ecologyandsociety.org/vol11/ iss1/art10/.

Pahl-Wostl, C. 2007a. The implications of complexity for integrated resources management. Environmental Modelling and Software 22:561-569.

Pahl-Wostl, C. 2007b. Transition towards adaptive management of water facing climate and global change. Water Resources Management 21(1):49-62.

Pahl-Wostl, C., G. Berkamp. and K. Cross. 2006. Adaptive management of upland rivers facing global change: general insights and specific considerations for the Rhone basin. Available online at: http://rosenberg.ucanr.org/documents/ Rosenberg Paper Pahl-Wostlcanada.pdf.

Pahl-Wostl, C., T. Downing, P. Kabat, P. Magnuszewski, J. Meigh, M. Schlueter, J. Sendzimir, and S. Werners. 2005. Transition to adaptive water management; the NeWater Project. NeWater Report, No. 1. NeWater Project, University of Osnabrück, Osnabrück, Germany. Available online at: www.newater.info.

Pahl-Wostl, C., and M. Hare. 2004. Processes of social learning in integrated resources management. Journal of Applied and Community Psychology 14:193-206.

Pahl-Wostl, C., C. C. Jaeger, S. Rayner, C. Schär, M. van Assel, D. M. Imboden, and A. Vckovski. 1998. Regional integrated assessment and the problem of indeterminacy. Pages 435-497 in $\mathrm{P}$. Cebon, U. Dahinden, H. C. Davies, D. M. Imboden, and C. C. Jaeger, editors. Views from the Alps: regional perspectives on climate change. MIT Press, Cambridge, Massachusetts, USA.

Panebianco, S., and C. Pahl-Wostl. 2006. Modelling socio-technical transformations in wastewater treatment - a methodological proposal.
Technovation 26(9):1090-1100.

Prato, A. 2003 Adaptive management of large rivers with special reference to the Missouri River. Journal of the American Water Resources Association 39(4):935-946.

Rees, J. 2002. Risk and integrated water management. TAC Background Papers, No. 6. Global Water Partnership, Stockholm, Sweden.

Richter, B. D., R. Mathews, D. L. Harrison, and R. Wigington. 2003. Ecologically sustainable water management: managing river flows for ecological integrity. Ecological Applications 13:206-224.

Rogers, P., and A. Hall. 2003. Effective water governance. TAC Background Papers, No. 7. Global Water Partnership, Stockholm, Sweden.

Sterman, J. D. 2000. Business dynamics: systems thinking and modeling for a complex world. McGraw-Hill/Irwin, Boston, Massachusetts, USA.

Tippet, J., B. Searle, C. Pahl-Wostl, and Y. Rees. 2005. Social learning in public participation in river basin management. Environmental Science \& Policy 8(3):287-299.

van Eeten, M. J. G., and E. Roe. 2002. Ecology, engineering, and management; reconciling ecosystem rehabilitation and service reliability. Oxford University Press, New York, New York, USA.

Walker, W., P. Harremoës, J. Rotmans, J. Van der Sluijs, M. Van Asselt, P. Jansen, and M. P. Krayer von Krauss. 2003. Defining uncertainty: a conceptual basis for uncertainty management in model-based decision support. Journal of Integrated Assessment 4(1):5-17.

Walters, C. J. 1986. Adaptive management of renewable resources. McGraw Hill, New York, New York, USA. 